BMJ

Paediatrics

Open

\title{
Management of children visiting the emergency department during out-of- office hours: an observational study
}

Gina Schinkelshoek (D) ,' Dorine M Borensztajn (D) ,' Joany M Zachariasse (D) , Ian K Maconochie, ${ }^{2}$ Claudio F Alves, ${ }^{3}$ Paulo Freitas, ${ }^{4}$ Frank J Smit, ${ }^{5}$ Johan van der Lei, ${ }^{6}$ Ewout W Steyerberg, ${ }^{7}$ Susanne Greber-Platzer, ${ }^{8}$ Henriëtte A Moll (D) ${ }^{1}$

To cite: Schinkelshoek G, Borensztajn DM,

Zachariasse JM, et al. Management of children visiting the emergency department during out-ofoffice hours: an observational study. BMJ Paediatrics Open 2020;4:e000687. doi:10.1136/ bmjpo-2020-000687

- Additional material is published online only. To view please visit the journal online (http://dx.doi.org/10.1136/ bmjpo-2020-000687).

Received 23 March 2020 Revised 11 June 2020 Accepted 12 June 2020
Check for updates

(C) Author(s) (or their employer(s)) 2020. Re-use permitted under CC BY. Published by BMJ.

For numbered affiliations see end of article.

Correspondence to Prof. Dr. Henriëtte A Moll; h.a. moll@erasmusmc.nl

\section{ABSTRACT}

Background The aim was to study the characteristics and management of children visiting the emergency department (ED) during out-of-office hours.

Methods We analysed electronic health record data from 119204 children visiting one of five EDs in four European countries. Patient characteristics and management (diagnostic tests, treatment, hospital admission and paediatric intensive care unit admission) were compared between children visiting during office hours and evening shifts, night shifts and weekend day shifts. Analyses were corrected for age, gender, Manchester Triage System urgency, abnormal vital signs, presenting problems and hospital.

Results Patients presenting at night were younger (median (IQR) age: 3.7 (1.4-8.2) years vs 4.8 (1.8-9.9)), more often classified as high urgent ( $16.3 \%$ vs $9.9 \%)$ and more often had $\geq 2$ abnormal vital signs ( $22.8 \%$ vs $18.1 \%)$ compared with office hours. After correcting for disease severity, laboratory and radiological tests were less likely to be requested (adjusted OR (aOR): $0.82,95 \% \mathrm{Cl} 0.78-$ 0.86 and a0R: $0.64,95 \% \mathrm{Cl} 0.60-0.67$, respectively); treatment was more likely to be undertaken (aOR: 1.56 , $95 \% \mathrm{Cl} 1.49-1.63$ ) and patients were more likely to be admitted to the hospital (aOR: 1.32, 95\% Cl 1.24-1.41) at night. Patterns in management during out-of-office hours were comparable between the different hospitals, with variability remaining.

Conclusions Children visiting during the night are relatively more seriously ill, highlighting the need to keep improving emergency care on a 24-hour-a-day basis. Further research is needed to explain the differences in management during the night and how these differences affect patient outcomes.

\section{INTRODUCTION}

Concerns exist that emergency care may differ during out-of-office hours, that is, evening, night and/or weekend shifts compared with office hours. For example, higher mortality rates were found during weekend visits in adult patients with sepsis presenting to the emergency department (ED). ${ }^{1}$ Some suggest that worse patient outcomes during outof-office hours can, partly, be explained by

\section{What is known about the subject?}

Concerns exist that emergency care may differ during out-of-office hours and office hours. There has been growing attention for paediatric emergency care at the emergency department (ED) recently. However, little is known about children visiting the ED during out-of-office hours.

\section{What this study adds?}

Children visiting the ED during the night were relatively more seriously ill than during office hours. Fewer diagnostic tests, more treatment and more hospital admissions were reported during the night, which could not be explained by correcting for illness severity.

higher illness severity and not by the time of arrival as an independent factor. ${ }^{23}$ When looking at the paediatric population, higher mortality rates were observed among children admitted to the paediatric intensive care unit (PICU) during out-of-office hours. ${ }^{4}$ However, other studies analysing PICU patients are in conflict with this finding. ${ }^{5-9}$

Over the past few years, increasing attention has been paid to paediatric emergency care, leading to different guidelines and standards for children visiting the ED. ${ }^{10-14}$ These guidelines aim to achieve optimal utilisation of available resources, optimise patient outcomes and thereby improve the quality of care. A recent study reported that main standards of care are fulfilled in European EDs, but some areas of improvement still exist. ${ }^{15}$

However, little research has focused specifically on children visiting the ED during out-ofoffice hours. Recently, variation in paediatric ED utilisation patterns and the presentation of these children by the shift of arrival has 
been reported. ${ }^{16}$ But this study was a single-centre study, which may limit generalisability. Moreover, no study has analysed resource utilisation at paediatric EDs during out-of-office hours, except for studies analysing children with a specific presenting problem. ${ }^{17-19}$

It is important to obtain insight into the characteristics and management of the whole paediatric patient population attending the ED with its variable presenting problems, as this may be helpful in optimising guidelines and resource allocation, thereby improving the quality of care on a 24-hour-a-day basis.

The aim of this study was to compare patient characteristics and management of paediatric patients visiting the ED during out-of-office hours to office hours in four different European countries.

\section{METHODS}

\section{Study design, setting and patients}

This study is part of the TrIAGE project (Triage Improvement Across General Emergency departments for paediatric patients), a prospective observational study. ${ }^{20}$ This project captured routinely collected, standardised, electronic health record data of all non-scheduled ED visits of children $<16$ years in five different hospitals in four different countries. The five participating hospitals, selected by convenience sampling, were: Erasmus Medical Centre, the Netherlands; Maasstad Hospital, the Netherlands; St Mary's Hospital Imperial College Healthcare National Health Service Trust, UK; Hospital Professor Doutor Fernando Fonseca, Portugal; and Vienna General Hospital, Austria. The enrolment period varied from 8 to 36 months between 2012 and 2015.

At the beginning of the study, a minimum dataset of variables for the collection was defined. If necessary, entries in the electronic health data were added or modified. Nurses at the ED were informed about the study and encouraged to fill in the entire medical records, including vital signs, which is in principle routine data. During the study, these routinely collected data were documented in the electronic, medical records by nurses at the ED. Data completeness and accuracy of the data were reviewed using a checklist of quality control. Sometimes, data were completed by information or vital signs from medical records documented by physicians at the ED. Coded data were extracted from the electronic hospital information systems and thereafter transferred to the principal investigator as an encrypted file. Careful data harmonisation and quality checks were conducted. The requirement for informed consent was obtained by all hospitals and the study was approved by the medical ethical committees of all participating institutions.

\section{Patient and public involvement statement}

Patients or the public were not involved in this research.

\section{Definitions}

Office hours versus out-of-office hours

Office hours were defined as Monday until Friday, between 08:00 and 17:59, also referred to as day shift week. We compared office hours, as reference shift, to out-of-office hours, divided into evening shifts, night shifts and day shifts during the weekend. Evening shifts were defined as Monday until Sunday between 18:00 and 22:59 and night shifts as Monday until Sunday between 23:00 and 07:59, based on the previous literature. ${ }^{5} 917$ Weekend day shifts were defined as Saturday and Sunday between 08:00 and 17:59.

\section{Patient characteristics}

For this study, the following data were extracted from the database: age, gender, time and date of arrival, Manchester Triage System (MTS) urgency, vital signs and presenting symptom (based on the MTS flowchart). The MTS urgency consists of five categories: emergent, very urgent, urgent, standard and non-urgent. ${ }^{21-23}$ These categories were divided into three groups: high urgent (emergent or very urgent, $<10$ min waiting time), urgent (urgent, $<60 \mathrm{~min}$ waiting time) and low urgent (standard or non-urgent, $\geq 60 \mathrm{~min}$ waiting time). Vital signs included heart rate, respiratory rate, oxygen saturation and temperature. Vital signs were considered abnormal based on the Advanced Paediatric Life Support reference values, with fever defined as temperature $\geq 38.5^{\circ} \mathrm{C}$. ${ }^{24}$ The MTS flowchart was used to create subgroups of presenting problems. These subgroups, based on a previous study, ${ }^{25}$ included medical (respiratory, ear, nose and throat problems, gastrointestinal problems, neurological or psychiatric problems, general malaise, urological or gynaecological problems, dermatological and others) and trauma (trauma or muscular and wounds) (online supplementary table 1.1).

\section{Management}

Management was defined as diagnostics (laboratory tests and imaging), treatment at the ED and hospital or PICU admission directly after ED visit. Laboratory tests were divided into blood tests, including cultures, and urine tests, including cultures. Imaging was divided into: X-ray, ultrasound and CT.

Treatment was divided into: oral medication, inhalation medication, intravenous medication or intravenous fluids and immediate lifesaving interventions (ILI) (online supplementary table 2 ). ${ }^{26}$

In the multivariable regression models, we defined laboratory diagnostics as any form of laboratory tests, radiological diagnostics as any form of imaging and treatment as any form of treatment.

Hospital admission included patients who were admitted to the general ward or the PICU. PICU admission was defined as admission to the PICU directly from the ED.

\section{Statistical analysis}

In descriptive statistics of patient characteristics, continuous, skewed variables are shown as median with IQR. 
Table 1 Missing data for vital signs and imputation model

\begin{tabular}{ll}
\hline Vital sign & $\begin{array}{l}\text { Missing \% of total patients } \\
\text { (interhospital range) }\end{array}$ \\
\hline Heartrate & $42.7(19.5-62.9)$ \\
Respiratory rate & $52.4(23.5-87.4)$ \\
Oxygen saturation & $44.9(19.7-66.4)$ \\
Temperature & $22.5(5.9-58.2)$ \\
\hline
\end{tabular}

Missing data for vital signs were imputed using a multiple imputation model including patient characteristics, date and time, triage items, vital signs, diagnostics, therapy and disposition after the ED. This imputation process resulted in 25 datasets on which statistical analyses were performed and pooled for a final result. ${ }^{27}$ Imputation was performed by using the MICE imputation package in R V.2.15.2.

ED, emergency department.

Nominal and ordinal variables are shown as the number of patients with percentage within the shift. Nominal and ordinal variables considering management are shown as percentages within the shift, with interhospital ranges.

In multivariable regression analyses, differences in management were compared between office hours and evening, night and weekend day shifts. To study the independent role of the shift of arrival, the regression analyses were adjusted for age, gender, MTS urgency, abnormal vital signs, presenting problem and hospital. We performed stratified analyses, by conducting the adjusted regression analyses for each hospital separately, to provide insight into interhospital differences.

Missing data for vital signs were imputed using a multiple imputation model (table 1). These missing data were assumed to be conditional on other variables included in the database, that is, missing at random (online supplementary 3). Sensitivity analyses were performed by analysing a database restricted to complete cases (online supplementary 4). ${ }^{27} 28$

Results were considered statistically significant at a $\mathrm{p}$ value of $\leq 0.05$.

Initial analyses were performed with SPSS software V.21 (IBM SPSS Statistics, IBM Corporation).

\section{RESULTS}

\section{Patient population}

In total, 119209 patients, $\leq 16$ years, visited the participating EDs. Five patients were excluded owing to missing arrival time or date, leaving 119204 patients for analysis, with 50417 (42.3\%) of these patients who visited the ED during office hours versus $68787(57.7 \%)$ during outof-office hours. Of those, $18220(15.3 \%)$ visited during weekend day shifts, 36429 (30.6\%) during the evening and $14138(11.9 \%)$ during the night.

Patients who visited the ED during the night were younger, were more often classified by MTS as high urgent and more often had two or more abnormal vital signs (table 2).

During office hours, general malaise $(20.0 \%)$, trauma or muscular (19.4\%) and gastrointestinal problems $(15.1 \%)$ were the most common presenting problems (figure 1). During the night, relatively more general malaise $(24.6 \%)$, gastrointestinal problems $(20.2 \%)$ and respiratory problems $(17.6 \%)$ and fewer trauma cases $(8.2 \%)$ were observed. Presenting problems during the evening and weekend day shifts were similar compared with office hours (online supplementary table 1.2).

\section{Management}

During out-of-office hours, fewer diagnostic tests, more treatment and more hospital and PICU admissions were conducted (table 3 ).

Table 2 Patient characteristics

\begin{tabular}{|c|c|c|c|c|}
\hline Total $(n=119204)$ & $\begin{array}{l}\text { Office hours* } \\
(n=50417)\end{array}$ & $\begin{array}{l}\text { Evening shift } \\
(\mathrm{n}=36429)\end{array}$ & $\begin{array}{l}\text { Night shift } \\
(n=14138)\end{array}$ & $\begin{array}{l}\text { Day shift } \\
(n=18220)\end{array}$ \\
\hline Median age, years (IQR) & $4.8(1.8-9.9)$ & $4.5(1.8-9.5)$ & $3.7(1.4-8.2)$ & $4.2(1.7-8.8)$ \\
\hline \multicolumn{5}{|l|}{ Gender, n (\%) } \\
\hline Male & $27150(53.9)$ & $19698(54.1)$ & $7566(53.5)$ & $9956(54.6)$ \\
\hline \multicolumn{5}{|l|}{ MTS, n (\%) } \\
\hline High urgent & $4963(9.9)$ & $4136(10.7)$ & 2302 (16.3) & 1683 (9.2) \\
\hline Urgent & $13300(26.4)$ & $10796(29.6)$ & $3655(25.9)$ & $4866(26.7)$ \\
\hline Low urgent & $31478(61.7)$ & $21276(58.4)$ & $7892(55.8)$ & $11366(62.4)$ \\
\hline Missing & $676(1.3)$ & $452(1.2)$ & $289(2.0)$ & $305(1.7)$ \\
\hline \multicolumn{5}{|l|}{ Vital signs, n (\%) } \\
\hline Normal & $18734(37.2)$ & $12903(35.4)$ & $4812(34.0)$ & $6553(36.0)$ \\
\hline 1 Abnormal & $22545(44.7)$ & $15947(43.8)$ & $6100(43.1)$ & $8119(44.6)$ \\
\hline 2 or more abnormal & $9139(18.1)$ & $7578(20.8)$ & $3227(22.8)$ & 3548 (19.5) \\
\hline
\end{tabular}

${ }^{*}$ Office hours=day shift week.

MTS, Manchester Triage System. 


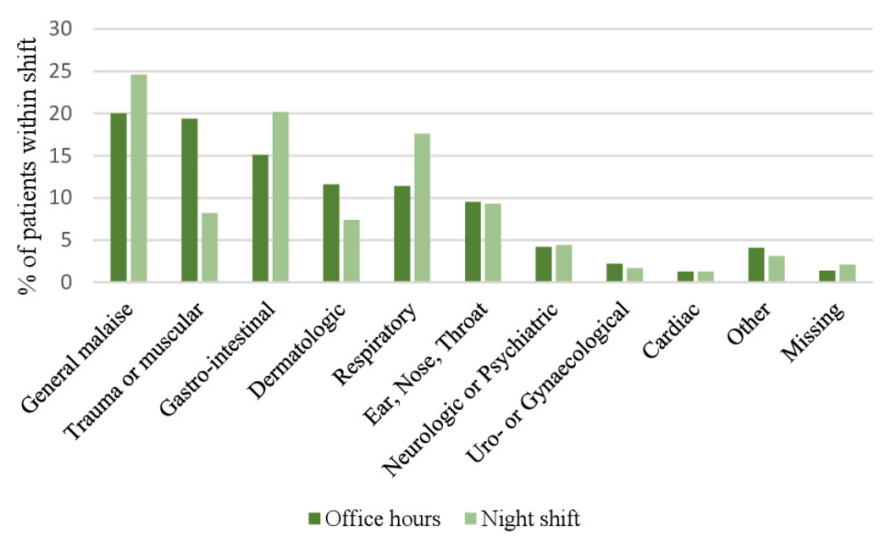

Figure 1 Presenting problems.

During the evening and weekend day shift, fewer urine and blood tests were performed. During the evening, night and weekend day shifts, imaging was performed less often, except for X-ray during the evening shift. Treatments with oral, inhaled and intravenous medication were given more often, especially during the night. Also, during the night, slightly more ILIs were seen, while more hospital and ICU admissions were observed.

In multivariable regression analyses, the results were adjusted for age, gender, urgency, abnormal vital signs, presenting problem and hospital (table 4).
Laboratory and imaging diagnostics were significantly less likely to be performed during the evening and night shifts. Also, patients were significantly more likely to receive treatment during all out-of-office hours shifts and more likely to be admitted to the hospital during the night shift. After adjusting, no association was found between PICU admission and out-of-office hours visits.

When analysing a database consisting only of complete cases for vital signs, overall results were comparable with the analyses in the imputation database (online supplementary 4).

\section{Interhospital analyses}

Hospital characteristics are shown in table 5 and online supplementary table 5.1-5.5. Some interhospital variation in management was observed (table 2). The multivariable regression analyses, adjusted for age, gender, urgency level, abnormal vital signs and presenting problem, were performed for each hospital separately in stratified analyses (online supplementary table 6). Overall patterns in management during out-of-office hours were comparable between the different hospitals, with some variation remaining. For example, at two hospitals, no significant difference was found in hospital admissions during the night. At another hospital, imaging was requested more frequently during evening and weekend shifts.

Table 3 Management (diagnostics, treatment, hospital admission and PICU admission), descriptive

\begin{tabular}{|c|c|c|c|c|}
\hline Total $(n=119204)$ & $\begin{array}{l}\text { Office hours }{ }^{*} \\
(n=50417)\end{array}$ & $\begin{array}{l}\text { Evening shift } \\
(\mathrm{n}=36429)\end{array}$ & $\begin{array}{l}\text { Night shift } \\
(n=14138)\end{array}$ & $\begin{array}{l}\text { Day shift weekend } \\
(n=18220)\end{array}$ \\
\hline \multicolumn{5}{|l|}{ Mean \% (interhospital range) } \\
\hline \multicolumn{5}{|l|}{ Laboratory diagnostics } \\
\hline Any laboratory test $(n=119204)$ & $22.2(11.7-40.6)$ & $18.6(9.2-33.0)$ & $21.5(9.8-40.0)$ & $20.2(8.0-33.3)$ \\
\hline Urine tests $(n=50473) \dagger$ & $20.2(11.0-23.5)$ & $17.1(8.1-22.3)$ & $20.2(13.9-23.2)$ & $16.6(7.7-19.6)$ \\
\hline Blood tests $(n=66029) \dagger$ & $21.9(11.7-26.7)$ & $15.2(9.2-20.3)$ & $20.4(9.8-30.5)$ & $17.2(7.9-23.5)$ \\
\hline \multicolumn{5}{|l|}{ Imaging diagnostics } \\
\hline$X$-ray $(n=119204)$ & $19.5(6.0-24.7)$ & $19.4(3.7-40.9)$ & $12.1(4.3-17.1)$ & $17.4(5.5-41.2)$ \\
\hline Ultrasound $(n=119204)$ & $2.7(1.5-6.0)$ & $1.7(0.5-2.9)$ & $1.2(0.5-4.1)$ & $2.2(0.6-4.2)$ \\
\hline CT $(n=119204)$ & $1.2(0.7-2.5)$ & $1(0.6-2.4)$ & $0.9(0.4-2.3)$ & $1(0.5-2.1)$ \\
\hline \multicolumn{5}{|l|}{ Treatment } \\
\hline Oral medication $(n=108621) \dagger$ & $13.9(8.0-34.3)$ & $17.2(8.6-41.8)$ & $23.5(14.9-45.1)$ & $16.5(8.2-39.7)$ \\
\hline Inhaled medication ( $\mathrm{n=119204)}$ & $6.5(3.6-8.7)$ & $6.5(3.5-9.0)$ & $12(6.0-15.4)$ & $6.9(3.5-9.8)$ \\
\hline IV medication or fluids $(n=119204)$ & $7.3(4.1-14.0)$ & $7(4.2-11.3)$ & $11.3(4.6-19.4)$ & $7.8(3.4-12.0)$ \\
\hline ILI (n=119204) & $0.3(0.0-1.1)$ & $0.3(0.0-1.2)$ & $0.5(0.0-1.9)$ & $0.4(0.1-1.2)$ \\
\hline \multicolumn{5}{|l|}{ Hospital admission ( $n=119204)$} \\
\hline Yes & $9.7(4.3-22.6)$ & $10.2(5.0-24.2)$ & $14.3(8.8-38.4)$ & $9.9(4.6-22.4)$ \\
\hline \multicolumn{5}{|l|}{ PICU admission ( $n=119204)$} \\
\hline Yes & $0.6(0.1-2.3)$ & $0.5(0.1-2.8)$ & $0.8(0.2-4.7)$ & $0.6(0.0-2.7)$ \\
\hline
\end{tabular}

*Office hours=day shift week.

†Not all variables were complete for all hospitals, making the total number less than 119204.

ILI, immediate lifesaving interventions; IV, intravenous; PICU, paediatric intensive care unit. 
Table 4 The association between management (laboratory tests, imaging, treatment, hospital and PICU admission) and time of arrival at the ED, adjusted regression analyses

\begin{tabular}{|c|c|c|c|c|}
\hline Total, n= 119204 & \multirow{2}{*}{$\begin{array}{l}\text { Office hours } \dagger \\
(n=50417)\end{array}$} & \multirow{2}{*}{$\begin{array}{l}\text { Evening shift } \\
(\mathrm{n}=36 \text { 429) }\end{array}$} & \multirow{2}{*}{$\begin{array}{l}\text { Night shift } \\
(n=14 \text { 138) }\end{array}$} & \multirow{2}{*}{$\begin{array}{l}\text { Day shift weekend } \\
(n=18 \text { 220) }\end{array}$} \\
\hline $\mathrm{aOR}^{\star}(95 \% \mathrm{Cl})$ & & & & \\
\hline \multirow[t]{2}{*}{ Laboratory tests } & - & 0.79 & 0.82 & 0.92 \\
\hline & - & $(0.76-0.82) \ddagger$ & $(0.78-0.86) \ddagger$ & $(0.87-0.96) \ddagger$ \\
\hline \multirow[t]{2}{*}{ Imaging } & - & 0.93 & 0.64 & 0.99 \\
\hline & - & $(0.89-0.96) \ddagger$ & $(0.60-0.67) \ddagger$ & $(0.94-1.04)$ \\
\hline \multirow[t]{2}{*}{ Treatment } & - & 1.11 & 1.56 & 1.17 \\
\hline & - & $(1.07-1.15) \ddagger$ & (1.49-1.63)‡ & $(1.12-1.22) \ddagger$ \\
\hline \multirow[t]{2}{*}{ Hospital admission } & - & 1.06 & 1.32 & 1.05 \\
\hline & - & $(1.00-1.11) \ddagger$ & $(1.24-1.41) \ddagger$ & $(0.99-1.12)$ \\
\hline \multirow[t]{2}{*}{ PICU admission } & - & 1.15 & 0.92 & 1.19 \\
\hline & - & $(0.95-1.42)$ & $(0.71-1.19)$ & $(0.93-1.52)$ \\
\hline
\end{tabular}

*Adjusted for age, gender, urgency, vital signs, presenting problem and hospital.

†Office hours (=day shift week) as reference shift.

$\ddagger P$ value $\leq 0.05$. If not stated: $p$ value $>0.05$.

aOR, adjusted OR; ED, emergency department; PICU, paediatric intensive care unit.

\section{DISCUSSION}

In this large observational study of 119204 visits in five EDs in Europe, we demonstrate differences in acuity level and management of children visiting the ED during outof-office hours compared with office hours.

We found that children visiting during the night were relatively more seriously ill. Second, after correcting for patient characteristics, illness severity and hospital, we observed fewer laboratory and radiological tests while children were more likely to receive treatment at the ED and to be admitted to the hospital especially during the night. No association was found between out-ofoffice hours visits and PICU admission, after statistically correcting for disease severity.

Overall, the trends in out-of-office hours care were comparable between the different hospitals, with variability remaining.

In a recent study, ED utilisation patterns of paediatric patients throughout the day was analysed. ${ }^{16}$ The distribution of visits over the evening and night shifts was quite similar to our results. Also, in line with our results, they observed that children during the night are relatively more ill. So, although the proportion of patients visiting during the night is the smallest, the acuity of this group is the highest, which shows the importance of the same quality of care on a 24-hour-a day basis. In contrast to our results, no association between the shift of arrival and hospital admission was reported. However, this was a single-centre study, which limits generalisability.

Variation in management during out-of-office hours, most pronounced during the night, could not be explained by illness severity. Reducing variation in care could result in lower resource utilisation and costs and could improve the use of time, space and staff. ${ }^{29}$ To obtain more standardised care, also during out-of-office hours, it is essential to understand which factors contribute to the differences we observed.

At first, different levels of staff during the night might influence management. Several studies found differences in resource use $\mathrm{e}^{30-34}$ and admission rates ${ }^{35}$ depending on physician background and experience.

Second, the availability of resources during night shifts, such as imaging resources or the availability of specialised radiologists to assess these results during the night, might contribute to the lower use of imaging during the night. ${ }^{36}$

Our results raise the question of whether these higher treatment and admission rates and the lower use of diagnostic imaging during the night might have been unwarranted and contribute to unnecessary costs. Earlier research reported that higher resource utilisation is related to higher costs, but not to lower admission rates. ${ }^{37-39}$ One of the hospitals in our study showed no difference in diagnostics during the night, in contrast to the other hospitals, but still showed higher admission rates compared with office hours.

We speculate that our results might also partly be explained by a more pragmatic approach of the patient during the night, resulting in fewer diagnostic tests, more treatment and more hospital admissions. The previous literature did report higher rates of antibiotic prescriptions ${ }^{17}$ and recommendations to admit to the hospital, ${ }^{40}$ in children visiting the ED during the night. Additionally, parental demand might contribute to these results. ${ }^{41}$ Furthermore, in contrast to general hospital admission, the higher rates of PICU admission during the night could be explained by illness severity and case mix. The indications for PICU admissions are more standardised compared with indications for general hospital and therefore less influenced by non-patient factors. 
Table 5 Hospital characteristics

\begin{tabular}{|c|c|c|c|c|c|}
\hline & $\begin{array}{l}\text { Erasmus MC- } \\
\text { Sophia Children's } \\
\text { Hospital, } \\
\text { Rotterdam, The } \\
\text { Netherlands }\end{array}$ & $\begin{array}{l}\text { Maasstad } \\
\text { Hospital, } \\
\text { Rotterdam, } \\
\text { The Netherlands }\end{array}$ & $\begin{array}{l}\text { St. Mary's Hospital } \\
\text { Imperial College } \\
\text { Healthcare NHS } \\
\text { Trust, London, UK }\end{array}$ & $\begin{array}{l}\text { Hospital Prof. } \\
\text { Dr. Fernando } \\
\text { Fonseca, } \\
\text { Lisbon, } \\
\text { Portugal }\end{array}$ & $\begin{array}{l}\text { General Hospital, } \\
\text { Vienna, } \\
\text { Austria }\end{array}$ \\
\hline $\begin{array}{l}\text { Hospital } \\
\text { characteristics }\end{array}$ & $\begin{array}{l}\text { University hospital } \\
60 \text { paediatric beds }\end{array}$ & $\begin{array}{l}\text { Teaching hospital } \\
59 \text { paediatric beds }\end{array}$ & $\begin{array}{l}\text { University hospital } \\
46 \text { paediatric beds }\end{array}$ & $\begin{array}{l}\text { Community hospital } \\
91 \text { paediatric beds }\end{array}$ & $\begin{array}{l}\text { University hospital } \\
134 \text { paediatric beds }\end{array}$ \\
\hline ED characteristics ${ }^{*}$ & $\begin{array}{l}6500 \text { children/year } \\
\text { Urban } \\
\text { Mixed high and } \\
\text { low socioeconomic } \\
\text { status }\end{array}$ & $\begin{array}{l}9500 \text { children/year } \\
\text { Urban } \\
\text { Generally low } \\
\text { socioeconomic } \\
\text { status }\end{array}$ & $\begin{array}{l}27000 \text { children/year } \\
\text { Urban } \\
\text { Mixed high and } \\
\text { low socioeconomic } \\
\text { status }\end{array}$ & $\begin{array}{l}60000 \text { children/year } \\
\text { Mixed urban/rural } \\
\text { Generally low } \\
\text { socioeconomic } \\
\text { status }\end{array}$ & $\begin{array}{l}22000 \text { children/year } \\
\text { Urban } \\
\text { Mixed high and } \\
\text { low socioeconomic } \\
\text { status }\end{array}$ \\
\hline $\begin{array}{l}\text { No of patients } \\
\text { included }\end{array}$ & 18590 & 10583 & 15556 & 53175 & 21300 \\
\hline Inclusion period & $\begin{array}{l}1 \text { January } 2012 \text { to } \\
31 \text { December } 2014\end{array}$ & $\begin{array}{l}1 \text { May } 2014 \text { to } 31 \\
\text { October } 2015\end{array}$ & $\begin{array}{l}1 \text { July } 2014 \text { to } 28 \\
\text { February } 2015\end{array}$ & $\begin{array}{l}1 \text { March } 2014 \text { to } 28 \\
\text { February } 2015\end{array}$ & $\begin{array}{l}1 \text { January } 2014 \text { to } \\
31 \text { December } 2014\end{array}$ \\
\hline \multicolumn{6}{|l|}{$\begin{array}{l}\text { No of patients } \\
\text { during, } n(\%)\end{array}$} \\
\hline Office hours & 8915 (48.0) & $4229(40.0)$ & 5635 (36.2) & $22470(42.3)$ & 9168 (43.0) \\
\hline $\begin{array}{l}\text { Out-of-office } \\
\text { hours }\end{array}$ & 9675 (52.0) & $6354(60.0)$ & 9921 (63.8) & $30705(57.7)$ & $12132(57.0)$ \\
\hline $\begin{array}{l}\text { Median age, years } \\
\text { (IQR) }\end{array}$ & $4.3(1.4-9.8)$ & $5.7(1.9-11.6)$ & $3.9(1.5-8.8)$ & $4.7(1.9-9.5)$ & $3.9(1.6-8.3)$ \\
\hline \multicolumn{6}{|l|}{ MTS, n (\%) } \\
\hline High urgent & $2427(13.1)$ & 1515 (14.3) & 1605 (10.3) & $6222(11.7)$ & $1084(5.0)$ \\
\hline Urgent & $8744(47.0)$ & $5110(48.3)$ & 3961 (25.5) & 10951 (20.6) & 3851 (18.1) \\
\hline Low urgent & 6849 (36.8) & 3857 (36.4) & 9990 (64.2) & $36002(67.7)$ & 15314 (71.9) \\
\hline Missing & $570(3.1)$ & $101(0.1)$ & $0(0.0)$ & $0(0.0)$ & $1051(4.9)$ \\
\hline \multicolumn{6}{|l|}{$\begin{array}{l}\text { Presenting problem, } \\
\mathrm{n}(\%)\end{array}$} \\
\hline Medical & $12.206(65.7)$ & $5163(48.8)$ & $11.520(74.1)$ & 43814 (82.4) & $19174(90.0)$ \\
\hline Trauma & 5814 (31.3) & $5321(50.3)$ & 4036 (25.9) & $9361(17.6)$ & $1034(4.9)$ \\
\hline Missing & $570(3.1)$ & $99(0.9)$ & $0(0.0)$ & $0(0.0)$ & $1092(5.1)$ \\
\hline
\end{tabular}

*All EDs are paediatric only, except for the Maasstad Hospital, which is mixed adult-paediatric. The Erasmus MC-Sophia Children's hospital has a mixed adult-paediatric ED since October 2014 (3 months in total during the inclusion period).

ED, emergency department.

These results point to the need for further research to explain the differences in clinical decisions during the night, by assessing differences in standards of care during out-of-office hours, such as availability of experienced staff and availability of diagnostics and equipment. ${ }^{14}$ Moreover, it is important to obtain insight into how these differences in management affect patient outcomes, for example, rehospitalisation, morbidity and 30-day mortality. Implementing guidelines for the management of children with specific conditions could help to reduce variation in management within and between hospitals, which optimise resource allocation and costs. Moreover, these guidelines could allow for better comparisons between the hospitals in further research.

Other studies on the topic of out-of-office hours care, including adult patients at the ED and paediatric patients at the PICU, described worse patient outcomes during the night and evening, represented by higher mortality rates. ${ }^{1442}$ We did not use mortality as the main outcome as the mortality in our dataset was very low (16 patients, $0.01 \%$ ), which is in line with the previous literature. ${ }^{43} 44$

\section{Strengths and limitations}

A major strength of this study is large number of patients from different centres, including both universities as teaching hospitals. This increases the generalisability of the results. Moreover, we adjusted for multiple variables concerning illness severity to analyse the independent role of time of the visit to management.

To appreciate the results, some limitations have to be considered. Hospitals were selected by convenience sampling, which influences the generalisability of the 
study. The enrolment period varied between the different hospitals. However, each hospital was followed for at least 8 months and in all hospitals a winter season was included to increase the comparability of the periods. Also, to our knowledge, there were no major changes or differences in for example vaccination status, occurrence of epidemics or other incidents during the total enrolment period (2012-2015).

Second, the analyses were based on routinely collected data. This results in some missing data, which we dealt with using multiple imputation for vital signs. The proportion of missing data for vital signs was comparable with previous studies ${ }^{4-47}$ and varied between the hospitals, which can be expected due to patient mix and differences in local policies.

Moreover, it is possible that there are more variables representing illness severity and influencing management, that were not included. These factors can be divided into patient-related and hospital-related factors. Patient-related factors are, for example, comorbidity, socioeconomic status or ethnic background. When looking at hospital-related factors, (experience level of) staff, resource availability and bed availability could possibly contribute to the differences in management. To deal with hospital-related differences, we adjusted our regression analyses for the hospital. Furthermore, we performed the regression analyses for each hospital separately. These stratified analyses demonstrated that overall results were comparable between the hospitals, but some variation remained. However, we did not have the specific information about the aforementioned hospital-level factors for each individual visit to include in the analyses. It would be interesting to analyse the potential effects of these factors in future research.

\section{CONCLUSION}

Children visiting during the night are relatively more seriously ill than those visiting during office hours. This highlights the need to keep improving emergency care on a 24-hour-a-day basis. Furthermore, differences in management are present depending on the time of the ED visit. Especially during the night, diagnostic tests are performed less frequently, while treatment is initiated more often and more children are admitted to the hospital than during office hours. These patterns are not explained by illness severity. Further research should focus on exploring the reasons for these differences and how these differences affect patient outcomes.

\footnotetext{
Author affiliations

${ }^{1}$ Department of General Paediatrics, Erasmus MC Sophia Children Hospital, Rotterdam, Zuid-Holland, The Netherlands

${ }^{2}$ Department of Paediatric Accident and Emergency, Imperial College Healthcare NHS Trust, London, UK

${ }^{3}$ Department of Paediatrics, Professor Doutor Fernando Fonseca Hospital, Amadora, Lisboa, Portugal

${ }^{4}$ Intensive Care Unit, Professor Doutor Fernando Fonseca Hospital, Amadora, Lisboa, Portugal
}

${ }^{5}$ Department of Paediatrics, Maasstad Hospital, Rotterdam, Zuid-Holland, The Netherlands

${ }^{6}$ Department of Medical Informatics, Erasmus Medical Center, Rotterdam, ZuidHolland, The Netherlands

${ }^{7}$ Department of Public Health, Erasmus Medical Center, Rotterdam, Zuid-Holland, The Netherlands

${ }^{8}$ Department of Pediatrics and Adolescent Medicine, Medical University of Vienna, Vienna, Austria

Contributors GS and DMB: conceptualisation, data curation, formal analysis, investigation, writing original draft, review and editing. JMZ: data curation, formal analysis, investigation, review and editing. SG-P, CFA, PF, FJS and IKM: data curation, investigation, review and editing. JvdL: conceptualisation, data curation, review and editing. EWS: data curation, review and editing. HAM: conceptualisation, data curation, investigation, project administration, supervision, review and editing.

Funding The authors have not declared a specific grant for this research from any funding agency in the public, commercial or not-for-profit sectors.

Competing interests None declared.

Patient and public involvement Patients and/or the public were not involved in the design, or conduct, or reporting, or dissemination plans of this research.

Patient consent for publication Not required.

Ethics approval Medical Ethics Committee Erasmus MC: MEC-2013-567 Raad van Bestuur Maasstad Ziekenhuis: Protocol L2013-103 Joint Research Complicance Office Imperial College London and Imperial College Healthcare NHS Trust: 14/WA/1051 Comissâo de Ética para a Saúde do Hospital Prof. Dr. Fernando Fonseca, EPE: reunião 06 Dezembro de 2017 Ethik Kommission Medizinische Universität Wien: 1405/2014.

Provenance and peer review Not commissioned; externally peer reviewed.

Data availability statement Data are available upon reasonable request. Data from this study are available upon request to the corresponding author of the study (h.a.moll@erasmusmc.nl), subject to local rules and regulations.

Open access This is an open access article distributed in accordance with the Creative Commons Attribution 4.0 Unported (CC BY 4.0) license, which permits others to copy, redistribute, remix, transform and build upon this work for any purpose, provided the original work is properly cited, a link to the licence is given, and indication of whether changes were made. See: https://creativecommons.org/ licenses/by/4.0/.

\section{ORCID iDs}

Gina Schinkelshoek http://orcid.org/0000-0001-8241-9750

Dorine M Borensztajn http://orcid.org/0000-0002-2437-0757

Joany M Zachariasse http://orcid.org/0000-0002-4093-8509

Henriëtte A Moll http://orcid.org/0000-0001-9304-3322

\section{REFERENCES}

1 Powell ES, Khare RK, Courtney DM, et al. The weekend effect for patients with sepsis presenting to the emergency department. $J$ Emerg Med 2013;45:641-8.

2 Mikulich O, Callaly E, Bennett K, et al. The increased mortality associated with a weekend emergency admission is due to increased illness severity and altered case-mix. Acute Med 2011;10:182-7.

3 Walker AS, Mason A, Quan TP, et al. Mortality risks associated with emergency admissions during weekends and public holidays: an analysis of electronic health records. Lancet 2017;390:62-72.

4 Arias Y, Taylor DS, Marcin JP. Association between evening admissions and higher mortality rates in the pediatric intensive care unit. Pediatrics 2004;113:e530-4.

5 Peeters B, Jansen NJG, Bollen CW, et al. Off-hours admission and mortality in two pediatric intensive care units without 24-h in-house senior staff attendance. Intensive Care Med 2010;36:1923-7.

6 McShane P, Draper ES, McKinney PA, et al. Effects of out-of-hours and winter admissions and number of patients per unit on mortality in pediatric intensive care. J Pediatr 2013;163:1039-44.

7 Thabet FC, alHaffaf FA, Bougmiza IM, et al. Off-Hours admissions and mortality in PICU without 24-hour Onsite intensivist coverage. $J$ Intensive Care Med 2020;35:694-9.

8 Hixson ED, Davis S, Morris S, et al. Do weekends or evenings matter in a pediatric intensive care unit? Pediatr Crit Care Med 2005;6:523-30. 
9 Numa A, Williams G, Awad J, et al. After-hours admissions are not associated with increased risk-adjusted mortality in pediatric intensive care. Intensive Care Med 2008;34:148-51.

10 American Academy of Pediatrics Committee on Pediatric Emergency Medicine, American College of Emergency Physicians Pediatric Committee, Emergency Nurses Association Pediatric Committee. Joint policy statement--guidelines for care of children in the emergency department. Ann Emerg Med 2009;54:543-52.

11 Gausche-Hill M, Wiebe RA. Guidelines for preparedness of emergency departments that care for children: a call to action. Ann Emerg Med 2001;37:389-91.

12 Remick K, Gausche-Hill M, Joseph MM, et al. Pediatric readiness in the emergency department. Pediatrics 2018;142:e20182459.

13 Royal College of Paediatrics and Child Health. Facing the future: standards for children in emergency care settings, 2018. Available: https://www.rcpch.ac.uk/sites/default/files/2018-06/FTFEC\% 20Digital\%20updated\%20final.pdf [Accessed Oct 2019].

14 Standards of Care for Children in Emergency Departments (Third version). International Federation for emergency medicine, 2012. Available: https://www.ifem.cc/wp-content/uploads/2019/06/ Standards-of-Care-for-Children-in-Emergency-Departments-V32019.pdf [Accessed Oct 2019].

15 Mintegi S, Maconochie IK, Waisman Y, et al. Pediatric preparedness of European emergency departments: a multicenter international survey. Pediatr Emerg Care 2020. doi:10.1097/ PEC.0000000000001934. [Epub ahead of print: 08 May 2020].

16 Almubarak H, Meckler G, Doan Q. Factors and outcomes associated with paediatric emergency department arrival patterns through the day. Paediatr Child Health 2019;24:323-9.

17 Roggen I, van Berlaer G, Gordts F, et al. Acute sore throat in children at the emergency department: best medical practice? Eur J Emerg Med 2015;22:343-7.

18 Johnson EK, Graham DA, Chow JS, et al. Nationwide emergency department imaging practices for pediatric urolithiasis: room for improvement. J Urol 2014;192:200-6.

19 Daverio M, Bressan S, Gregori D, et al. Patient and process factors associated with type of first neuroimaging and delayed diagnosis in childhood arterial ischemic stroke. Acad Emerg Med 2016;23:1040-7.

20 Zachariasse JM, Nieboer D, Maconochie IK, et al. Development and validation of a paediatric early warning score for use in the emergency department: a multicentre study. Lancet Child Adolesc Health 2020;4:583-91.

21 De Caluwé R, Manchester Triage G. Triage voor de spoedeisende hulp. Elsevier Gezondheidszorg, 2007.

22 van Veen M, Steyerberg EW, Van't Klooster M, et al. The Manchester triage system: improvements for paediatric emergency care. Emerg Med J 2012;29:654-9.

23 Mackway-Jones K, Marsden J, Windle J. Emergency triage: Manchester triage group. 3rd ed. Oxford, UK: John Wiley \& Sons, 2013.

24 Turner NM. Advanced paediatric life support. In: Druk V, ed. De Nederlandse editie. Houten: Bohn Stafleu van Loghum, 2017.

25 Zachariasse JM, Seiger N, Rood PPM, et al. Validity of the Manchester triage system in emergency care: a prospective observational study. PLoS One 2017;12:e0170811.

26 Lee JY, Oh SH, Peck EH, et al. The validity of the Canadian triage and acuity scale in predicting resource utilization and the need for immediate life-saving interventions in elderly emergency department patients. Scand J Trauma Resusc Emerg Med 2011;19:68.
27 Donders ART, van der Heijden GJMG, Stijnen T, et al. Review: a gentle introduction to imputation of missing values. J Clin Epidemiol 2006;59:1087-91.

28 Sterne JAC, White IR, Carlin JB, et al. Multiple imputation for missing data in epidemiological and clinical research: potential and pitfalls. BMJ 2009;338:b2393.

29 Neuman MI, Chiang VW. Variation in pediatric care at US hospitals. Pediatrics 2013;132:369-70.

30 Pitts SR, Morgan SR, Schrager JD, et al. Emergency department resource use by supervised residents vs attending physicians alone. JAMA 2014;312:2394-400.

31 White AL, Armstrong PAR, Thakore S. Impact of senior clinical review on patient disposition from the emergency department. Emerg Med J 2010;27:262-5. 96

32 Hampers LC, Faries SG. Practice variation in the emergency management of croup. Pediatrics 2002;109:505-8.

33 Melo MR, Ferreira-Magalhães M, Flor-Lima F, et al. Dedicated pediatricians in emergency department: shorter waiting times and lower costs. PLoS One 2016;11:e0161149.

34 Knapp JF, Simon SD, Sharma V. Variation and trends in ED use of radiographs for asthma, bronchiolitis, and croup in children. Pediatrics 2013;132:245-52.

35 Scott-Jupp R, Carter E, Brown N. Effects of consultant residence out-of-hours on acute paediatric admissions. Arch Dis Child 2020;105:661-3.

36 Fullerton K, Depinet H, lyer S, et al. Association of hospital resources and imaging choice for appendicitis in pediatric emergency departments. Acad Emerg Med 2017;24:400-9.

37 Kharbanda $A B$, Hall M, Shah SS, et al. Variation in resource utilization across a national sample of pediatric emergency departments. J Pediatr 2013;163:230-6.

38 Florin TA, French B, Zorc JJ, et al. Variation in emergency department diagnostic testing and disposition outcomes in pneumonia. Pediatrics 2013;132:237-44.

39 Bourgeois FT, Monuteaux MC, Stack AM, et al. Variation in emergency department admission rates in US children's hospitals. Pediatrics 2014:134:539-45.

40 El Khoury AC, Durden E, Ma L, et al. Perception and management of fever in infants up to six months of age: a survey of US pediatricans. BMC Pediatr 2010;10:95.

41 Pachter LM, Ludwig S, Groves A. Night people: utilization of a pediatric emergency department during the late night. Pediatr Emerg Care 1991;7:12-14.

42 Duvald I, Moellekaer A, Boysen MA, et al. Linking the severity of illness and the weekend effect: a cohort study examining emergency department visits. Scand J Trauma Resusc Emerg Med 2018;26:72.

43 Lopez E, Udaondo J, Olabarri M, et al. Mortality in Spanish pediatric emergency departments: a 5-year multicenter survey. Eur J Emerg Med 2017;24:392-7.

44 O'Malley P, Barata I, Snow S, et al. Death of a child in the emergency department. Pediatrics 2014;134:e313-30.

45 van de Maat J, Jonkman H, van de Voort E, et al. Measuring vital signs in children with fever at the emergency department: an observational study on adherence to the NICE recommendations in Europe. Eur J Pediatr 2020;179:1097-106.

46 Gravel J, Opatrny L, Gouin S. High rate of missing vital signs data at triage in a paediatric emergency department. Paediatr Child Health 2006;11:211-5.

47 Seiger N, van Veen M, Almeida H, et al. Improving the Manchester triage system for pediatric emergency care: an international multicenter study. PLoS One 2014:9:e83267. 